\title{
Social Rituals of Pain: The Socio-Symbolic Meaning of Violence in Gang Initiations
}

\author{
Jeffrey Stevenson Murer ${ }^{1}$ (D) Tilman Schwarze $^{1}$ \\ Accepted: 16 October 2020 / Published online: 23 October 2020 \\ (C) The Author(s) 2020
}

\begin{abstract}
Much of criminological scholarship on street gangs focuses on the deviant and delinquent aspects of gang violence. Although the research tradition acknowledges that violence is central to the life in a gang, it often labels this form of violence as an "anti-social" behaviour. This article challenges this conceptualisation of gang violence and proposes instead that gang violence is a social performance. By using the example of gang initiation rites, this article suggests that violence in such rites possesses a sociosymbolic and performative function that informs about the social status of gang members. This article draws on Jeffrey Stevenson Murer's theory of the performative and communicative function of violence as well as on Pierre Bourdieu's concepts of social field, habitus and social capital in order to demonstrate that violence during gang initiation rites is an inherently social act that reinforces and strengthens the social ties and bonds among the members of a gang. The aim of this piece is to broaden scholarship on gangs towards a more critical theorisation of the performative and communicative functions of gang violence. We suggest that a stronger engagement with critical social theory on collective identity, violence and social capital can contribute to a more nuanced understanding of the socio-symbolic and cultural processes that underlie gang membership.
\end{abstract}

Keywords Gangs · Violence · Initiation rites · Social capital · Performativity

\section{Introduction}

In the Saturday of 13 August 2011 edition of The Independent, an anonymous youth worker describes the disturbing "choices" faced by many of his clients when they are to be initiated

Jeffrey Stevenson Murer

jsm14@st-andrews.ac.uk

School of International Relations, University of St Andrews, Arts Faculty Building, Library Park, The Scores, St Andrews, Scotland KY16 9AX, UK 
into a gang. In this particular instance, the youth case worker described how his client either had to attack and stab another youth on the street or eat dog faeces. ${ }^{1}$ It was salacious piece of writing, especially coming only days after the rioting in the London boroughs of Hackney, Croydon, and Tottenham. Then Prime Minister David Cameron immediately blamed the unrest on "criminal gangs", depicting young people as outside the norms of society, who would "feel the full-force of the law". 2 Across the web, there are numerous stories of horrific gang initiation practices, some compiled into shock "top ten lists". ${ }^{3}$ Such lists or compilations include some variations on the "choices" above - to attack a rival gang member or a random person on the street. However, one scenario, which is included in such lists, but is more often described by gang members themselves or those academics who study gangs is a variation on the notion of being "jumped-in" or "beaten-in", where the initiate must endure a series of beating from soon to be fellow gang members. Elaine Salo describes such an initiation in piece exploring masculinities in the Manenberg township of Cape Town, in South Africa. She describes how new initiates to the Junky Funk Kids must face a gauntlet of fifty to ninety fellow members armed with clubs, leather belts, sticks, and other hand weapons. The initiates must walk the gauntlet without grimacing, resisting, or expressing pain: to show that you have "strong bones". One respondent explained: "You must demonstrate that you have strong bones...when your brother is in trouble you must be able to assist him" (Salo 2007:167). But these encounters are more than tests for the future. They are rituals.

Beyond the sensational, most likely apocryphal choices of eating dog faeces or similarly distasteful or revolting options, these are social rituals that require bodily commitments. In the case that Salo describes we are drawn to focus on the ritual of pain, the walking of the gauntlet without flinching, receiving the blows without complaint, and wholly committing one's body to the use by comrades to be and in a demonstration of submission and self-sacrifice. But there is the other component to these events: the ritual of violence, the willingness to inflict pain on a soon to be comrade, who may already be a friend or a relative, or both. This too is a demonstration of commitment: to unflinchingly inflict pain on to whichever body directed by the leadership of the group or as circumstance requires. This article explores the sociosymbolic meaning of violence during gang initiation rites. In particular, it offers a critical reading of the performative and communicative meaning of violence during such rites, and how prospective gang members, who take part in such rituals in order to become full members of a gang, are able to generate social capital by withstanding the violence during this initiation.

The piece draws on a critical scholarship that conceptualises violence not as something antisocial, but which rather highlights its social, cultural and identity-establishing function within certain social networks such as street gangs. We extensively engage with Jeffrey Murer's (2014) previous work on the performative and communicative qualities of violence. We, in turn, extensively draw on Pierre Bourdieu's conceptualisations of habitus, social field and social capital to describe the processes of accruing social status. We look to demonstrate that gang violence - particularly in the context of gang initiation rites - cannot be understood without considering the socio-cultural processes that underlie such performances of violence. In this respect, we suggest a conceptualisation of gang violence that does not follow orthodox criminology's labelling of gang violence as a form of "anti-social" behaviour, but rather

\footnotetext{
${ }_{1}^{1} \mathrm{https}$ //www.independent.co.uk/news/uk/crime/inside-the-dark-world-of-the-gang-initiation-ceremonies2336868.html

${ }^{2}$ Euronews August 9, 2011, http://www.euronews.com/2011/08/09/cameron-rioters-will-feel-full-force-of-thelaw/, accessed 22 August.

${ }^{3}$ https://www.ranker.com/list/horrible-initiation-rituals/harrison-tenpas
} 
suggests that the performance of violence in the context of gangs - particularly in the context of initiation rites - is an inherently social act that reinforces, strengthens and promotes social ties among gang members, and affords the accrual of social status to a gang member who either commits a violent act, or who withstands the violence in the case of an initiation rite. In other words, violence within gangs is considered to be a group norm, and therefore "committing violence can be seen as the means of developing social capital with a view to increasing social status" (Murer 2014, 311). Thus, the aim of this article is to offer a more theoretical and critical approach to the study of gang violence that highlights the social and communicative function of violence.

\section{Rituals of Pain}

Although gang initiation rites are not always required in order to become a full gang member, some of these initiations can take place through the process of being "jumped in" or "beaten in" (Karlin 2008, 60). In this process, established gang members beat an aspirant for a certain amount of time in order to introduce him or her as a new member to the gang. In such a form, gang initiations are a form of baptism that "functions as a ritual ceremony to show admittance and dedication to the gang" (Vigil 1996, 149). Hobsbawm argued with respect to the functions of initiation rituals that through "the heightened ceremony which surrounded the initiation of a man into a specific group of his fellow, one designated to demonstrate its utter difference from other groups and binds him to it by the strongest conceivable links" $(1959,154)$. In this way, the aspirant provides a bodily commitment to group, offering his body, pain and suffering. His pain at the hands of his would-be fellow members is the shared pain that all feel, if a member is harmed by someone from outside of the group membership. Simmel discussed such rituals in the context of secret societies: "through the symbolism of the ritual, which excites a whole range of vaguely delimited feelings beyond all particular, rational interests, the secret society synthesizes those interests into a total claim upon the individual" (1950, 360). What Simmel describes here is quite similar to Ariel Glucklich's (2001) discussion of "sacred pain" or the ritual use of pain in religious ceremony and society. Glucklich argues that "religious pain affects the identity of the individual subject and her sense of belonging to a larger community" $(2001,6)$. In the first instance voluntary pain is an act of submission, a bodily commitment, in Glucklich's example, to a religious experience. But it is also the demonstration of a willingness to enter a community, and in this way shared pain is the connection in such a religious community. Or as Kathleen Roberts Skerrett put it: "pain is an event of consciousness". It is the transformation of the body/self where "the link between ritual violence and consciousness is the lived experience of pain" $(2002,681)$. Those who are willing to submit to ritual pain "accept pain as necessary, even as a gift, because they view the transformation of the body self into a new sense of identity and embodiment" (682) as worthwhile.

Alan Morinis examined the role of pain in ritual more than 35 years ago, in a broad exploration of the reports from anthropologists that "record a consistent, deliberate, direct experience of pain as a remarkably recurrent aspect of adolescent initiation ritual" $(1985,152)$. He argues that the violence and the pain it produces in these ceremonial rites are not evidence of "barbaric, sadistic, blood thirsty torture being perpetrated by adults on the youth of their societies" but rather that there is an important role that "ordeal" plays in the transformation of person into a member of a defined social group. He explored how the pain itself could be play "central role in the accomplishment of the explicit purpose of the initiation" rite $(1985,150)$. 
While many early twentieth century anthropologists focus on the physical effects of these violent rituals, such as Arnold van Gennep in his 1909 The Rites of Passage where he observed that the experience of painful acts such circumcisions, amputations, brandings, or cauterisations, "leaves ineradicable traces that the incorporation into the group is permanent" (72 in Morinis 1985:153), Morinis focuses on the pain itself, which he characterises as an "ordeal". The ordeal is a complex and deeply intense experience. While not all rituals include pain, we can see from Morinis' exploration that there is an intense bond built between those who have shared experience.

Three more recent studies, however, make this link explicit. Harvey Whitehouse and his collaborator Jonathan Lanman argue that when people "undergo painful or frightening life experiences, they remember them as life-shaping episodes" and that "strengthens the impression that only those who have experienced the same thing can possibly understand how it feels and what it means" (2014: 681). They conclude that participation in dysphoric rituals prompts more intense experiences and prompt greater identification with the group (2014:684). The participants have their identities fused together, "through emotions and particularly the pain and trauma that bind people together" (Lende 2014: 686). This was also the finding in a 2013 study published in Psychological Science with the explicit title "Extreme rituals promote prosociality" (Xygalatas et al. 2013), The pain provides meaning, as a sense of shared experience binding individuals together. This is found even at an experimental level between test subjects who do not know one another. Brock Bastian, Jolanda Jetten and Laura Ferris found that "shared pain increases participation" in experimental settings, even when the pain is only holding one's hands under freezing water for $90 \mathrm{~s}$ or eating a hot bird's eye chilli for $2 \mathrm{~min}$ (2014), They found that "sharing painful experiences with other people, compared with a no-pain control treatment, promoted trusting interpersonal relationships by increasing perceived bonding among strangers and increased cooperation" (2014:2079). They argue that "shared pain may be an important trigger for group formation" (2014:2079). The pain they explored was physical pain at a minor level, and yet their findings were significant. In all of these studies, the social transformation bonding individuals to the group and one another is through the shared experience of the emotion of pain, this is also found in the work of Vamik Volkan.

Volkan, the psychoanalytic commentator on large group identity and international politics, suggests that a "chosen trauma" creates far greater identity bonds than what he calls "chosen glories". Everyone would like to be associated with a victory or a glory; it is a special form of identification to choose to be associated with defeat, loss, injury, or humiliation (Volkan 2009:9, Murer 2009:123). The intense emotional experiences of moving through the Junk Funk Kids' gauntlet - the fear, the apprehension, the sensations, the relief when it ended, the difference between the pain of the blows being administered and the pain of the wounds healing - cannot be adequately described to someone who has not experienced them. Similarly, they need not be described to someone who has experienced them. As with Volkan's "chosen trauma" there are no words to express the depth of the pain to someone unfamiliar with it, and no need for words to someone who is familiar. This is the basis of the bond; it is beyond language. This would be a completely different application of what Elaine Scarry meant when she wrote the "physical pain does not simply resist language it destroys it" (1985: 4). But here, we might see that pain is the basis of a bond beyond language. Further, in very recent research, Dimitry Xygalatas and his colleagues from Psychology, Biology, and Religious Studies, found that not only did many people endure pain as an ordeal of ritual passage and find that it was beneficial and fulfilling, but more that, those of ill health or lower economic status "sought out more painful levels of engagement" so as to counter any possible 
prejudice of stigma that they might not "truly" deserve to belong to the group $(2019,699)$. We can see a connection between Xygalatas and Morinis, when the latter writes that "the avoidance of pain and suffering is an instinctive human trait" $(1985,164)$, to seek it out, to ask for more or more intense pain, becomes part of a symbolic transformation, to alter one's social relations, and social standing, to demonstrate a commitment to the group and those within it, and a willingness to share the pain that is asked of the initiates. The immediate quality of pain as experience then becomes transformed into a form of social capital. It is here that we can see the social in violence.

Although Hobsbawm and Simmel captured the symbolism of initiation rites for the individual who intends to become part of a collective group and its collective identity in which the latter "is drawn from the shared identifications of individuals" (Murer 2009, 112), the difference of their understanding of initiations to gang initiations, however, is the actual means in becoming a member of a gang, namely the acceptance of physical violence against oneself. Criminological scholarship on gangs agrees upon that physical violence often forms an integral part of the life within a gang (Carlock and Lizotte 2015). For example, scholarship has identified that gang members are more likely to carry firearms than non-gang adolescents (Bjerregaard and Lizotte 1995) which, in turn, increases the level of violence (Fagan and Wilkinson 1998). In the context of gang initiations, Decker argues that violence "reinforce[s] the ties between members while reminding them that violence lies at the core of life in the gang" (1996, 255; see also Descormiers and Corrado 2016; Decker and Van Winkle 1996; Jankowski 1991; Spergel 1995; Vigil 1988). Papachristos, in his study of gang homicides, stresses that they kill because they live in a structured set of social relations in which violence works its way through a series of connected individuals. The gang qua group carries with it a set of extra-individual adversaries and allies that shape individual choices of action, including the selection of murder victims. As corporate actions between groups, gang murders do not end with the death of the victim but persist in the organizational memory of the gang, which is governed by norms of retaliation and violent mechanisms of social control (2009, 75-76).

Wood (2014) proposes that violence against rival gang members increases the reputation and social standing of the member who commits the violent act (see also Cohen 2018; Friedman et al. 1975). Deuchar (2010, 265-266) conceptualizes gang violence as something that gives gang members a sense of social bonding in an urban environment that is characterised by marginalisation, social and economic inequality and exclusion.

This paper contributes to this scholarship on the relationship between gangs and violence by arguing that violence within gangs-particularly, but not exclusively, in context of initiation rites - is not an action that only occurs between the perpetrator and the victim of violence. Rather, violence during a gang initiation rite is always "a form of communication that is accessible, easily perceived and easily understood" (Murer 2014, 289) by a third party which is not directly involved in the violent act between performer and victim. Put differently, the performance of violence in an initiation rite into a gang occurs within a triangular relationship between the performer (established gang members who is committing violence at any given moment), the target (aspirant who wants to become a gang member) and the audience (other established gang members who observe and judge the quality) of violence.

Two implications from such a conceptualisation of violence arise: first, a violent initiation ritual into a gang does not merely inform the status of membership of the aspirant (i.e. member of the gang or not), but, more importantly, it also demonstrates the aspirant's adherence to the values and norms of the life in a gang. In other words, if, as Decker argues, "violence lies at the core of life in the gang" $(1996,255)$, and therefore forms part of the collective identity and 
value system of a gang, then the willingness to undergo the violent initiation into a gang communicates to the established gang members that the aspirant accepts violence as an inherent feature of the value and norm system of the gang. A second implication-one which is closely related to Wood's (2014) observation that violence against rival gang members increases the reputation and social standing of the member who commits the violent act, and Deuchar's (2010) analysis that participating in gang violence gives a sense of social bonding (see also Deuchar 2009) - is that the violence during an initiation rite increases the aspirant's social capital within the gang: accepting the beating during the initiation without objection demonstrates that the aspirant is tough enough to become a member of the gang. This, in turn, increases the aspirant's level of social capital among the established members of the gang. Hence, the violent initiation alters the identity of the aspirants and it reduces the social distance to the other members of the gang who also "jumped into" the gang before (Skarbek and Wang $2015,298)$. It reinforces the shared experience as social bond.

Violence in the context of gangs possesses a social dimension which becomes only apparent if one considers the way people, who are not directly involved in the violent act, perceive such violence. Consequently, violence in the context of gangs is not "anti-social". In fact, it is very much social, as it informs about a gang member's adherence and commitment to the value and norm system of a gang. This line of argument resembles Emler and Reicher's argument about the visibility of deviance and the social character of "anti-social" behaviour. They argue that "anti-social behaviour is social in two senses. It is a socially visible activity and it is also frequently a group activity. [...] There is very little of significance that people do, good or bad, legal or illegal, which is not done in the company or with the knowledge, direct or indirect, of those who know them" (1995, 120-121). Consequently, violence in the context of gang initiation rites is committed not only with the knowledge and support of other people (first indicator of its social character), but also for enhancing the social standing of the aspirant among the other gang members (second indicator for the social character of violence). This does not mean, however, that other violent activities by gangs do not follow a similar pattern. In fact, we would argue that this "violence triangle" (Murer 2014) can be applied to other cases and forms of gang violence.

\section{The Social Audience of Violent Acts}

In his article, The Phenomenon of Violence, Riches (1986) argues that violence does not only constitute a bilateral relationship between the performer and the target, but rather a triangular relationship that also includes the witnesses of the act: "violence now comes to be seen as 'an act of physical hurt deemed legitimate by the performer and illegitimate by (some) witnesses"” (1986, 8). In an advancement of Riches' (1986) violence triangle, Bufacchi argues that one should change the term "witness" for the term 'spectator' because the spectator provides an impartial perspective "from which the claims of the other two agents can be critically examined" (2007, 34).

Based on these two theoretical elaborations, Murer (2014) develops a violence triangle that mainly focuses on the relationship between performer and audience. He criticises Riches's (1986) and Bufacchi's (2007) approach for being still too concerned with the bilateral relationship between performer of violence and the victim, "where the witness or the spectator appear as separate, or perhaps neutral, third-parties who observe an act of violence and adjudicate its legitimacy post hoc" (2014, 302). Rather, for Murer (2014), the primary relationship in violent acts is between the performer and an audience of that violent act. 
"The performer is not merely concerned with whether the audience will see the act of violence as legitimate or not, but rather the audience is making a determination as to whether the act conforms to the collective norms and values as embodied in social capital" (ibid.). In other words, the audience gives the violent act a social context in which the performance of violence is judged and evaluated in accordance with the values and norms of this audience. It is only through this social context that violence obtains a social meaning because "violence without an audience will still leave people dead, but is socially meaningless" (Schröder and Schmidt 2001; 5-6). Put differently, the audience as the public spectator perceives this violent act and determines whether it conforms to its social values and norms (Beck 2011, 347). Therefore, if the violent act must conform to the norms and values of the group, violence forms part of the group's self-conception (Murer 2014, 304). In this regard, violence may be employed to gain respect, may be an assertion of identity (Heitmeyer and Anhut 2008, 30), a shared group value, and an activity that serves as a means to strengthen collective identity (Kurtz and Turpin 1997 209).

As argued by several scholars, the initiation rite into a gang "determine[s] whether a prospective member is tough enough to endure the level of violence he or she will face as a gang member" (Decker 1996, 254; see also Best and Hutchinson 1996, 399; Stretesky and Pogrebin 2007, 89; Jankowski 1991, 49). If the prospective gang member does not communicate this strength by accepting the beating, he or she will not be able to belong to the group. In such an initiation the extent to which the established gang member hurts the aspirant during the initiation is less important than what the communicative meaning to the other gang members would be if the aspirant were to fight back. At the same time, however, withdrawing from the violent initiation also reduces the aspirant's social standing among the established gang members: "not to participate in violence, or not to abide by the norms of the group [...] expose[s] oneself to the potential of social sanction [...] [and] isolation" (Murer 2014, 303). Violence in gang initiations therefore gives an answer to the question "are you one of us?" (Dalal 2009, 74, original emphasis), and it determines whether the group upholds or loosens its social boundaries to the aspirant (Bowman 2001, 27).

However, the communicative and performative quality of violence in gang initiations is not only a one-way articulation of the gang towards the aspirant to accept violence as a required means for belonging to the group and to be part of their collective identity. It is also a reassurance and a re-experience of the gang members' own baptism and it connects them with the newcomer (Vigil 1996, 152). In other words, it "creates and reaffirms that which is sacred for the community" (Karlin 2008, 61). At the heart of the sacred is violence and the demonstration of the ability to withstand violence (Girard 1977, 32). Therefore, the experience of violence during the initiation to a gang creates a persistent feeling of sameness among the gang members; a sense of belonging (Volkan 2009, 4) that is shared by every member of the gang. It becomes a central part of the collective identity of the group (Lauger 2020), and it helps to create a "situated self" within that group (Stretesky and Pogrebin 2007, 89).

In light of this analysis, gang violence, then, is not a behaviour or activity that is anti-social. Rather, acts of violence in the context of gangs are always social actions between performer, target and audience with the aim of communicating something that has to conform to the norms and values of the gang. The audience is not separate, neutral or even a third party to the violent event (Murer 2014, 302), but rather constitutes the primary reference object of the same: the violent beating occurs precisely for the reason of communicating to the audience that the prospective gang member is tough enough to deal with the violent life within a gang. The prospective gang member has to conform to the values and norms of the gangs - norms and 
values which are often associated with violence. Thus, if one conceptualises gang violence in this triangular relationship, violence, then, is invariably a social act, serving the purpose of communication and social interaction between different individuals involved in this event.

Research on the role of masculinity and gender relationships in gangs confirms the social importance of violence. For example, in their study on young men's gendered narratives of violence in gang contexts, Cobbina et al. (2010) argue that while young men view violence among themselves as an expected norm in order to establish a masculine street reputation and identity, they view violence among young women as emotionally driven and even "stupid" because violence often originates from "stupid" motifs such as gossip and jealousy. Baird (2017), in his study on the role of masculinity in gang violence in Medellín, Colombia, argues that '[b]ecoming a gang member requires learning and displaying 'badness', a necessary rite of passage central to the ganging process. Badness is the 'strategic essentialisation' of certain hegemonic masculine performances within the gang, particularly those associated with violence" (2017: 203). Research on girls in gangs demonstrate that violence is important in order to establish reputation, for the accumulation of "street capital" (Sandberg 2008), and for the development of self-conceptions of femininity (Ness 2004; Dziewanski 2020, see also Otto 2020).

It is relatively easy to expand the finding on the social character of violence in initiation rites also to other acts of violence in the context of gangs. For example, the same social mechanisms operate in the context of inter-gang rivalry. As succinctly stated by Murer, which is worth quoting at length here:

one can easily imagine a scenario in which a young man walking down the street with other members of his street crew, the Blues, encounters a person symbolically signalling membership in a rival gang, the Reds. In the violent imaginary of the Blues street crew, there is no question of the moral superiority of the position of the Blues and the polarised relationship between "Us" and "Them". There is no ambiguity as to the legitimacy of the use of violence against the "threatening-rival-enemy". In this encounter with the rival-other, our young man's primary social concern is not with the Red, but with his social standing and status among his social-peer Blues. He then pulls a knife and attacks the rival member of the Reds. The relationship between the performer or the violence and the target is largely a structural one, whereas the relationship between the performer and the audience is a social and intersubjective one. In this case, violence is not maladaptive or anti-social, but rather is expected and constitutes the means to obtaining or accruing further social capital $(2014,302)$.

Thus, the introduction of the violence triangle between performer, target and audience into gang research enables to analyse gang violence not as a bilateral act between perpetrator and victim, but rather as a social performance which predominantly serves an audience in this violent act to figure out whether the victim's performance and behaviour during that violent encounter is consistent with the gang's shared values and norms.

Furthermore, there is an on-going but imperfect relationship between the performer and the audience. Frequently the performer will act in anticipation of what is expected of him regarding the possible accrual of social capital through performance. The audience need not dictate the specificity of the performance, but rather the performer anticipates what is expected. This can result in a number of different outcomes that include but are not limited to the performer correctly anticipating what is expected by the audience, and the audience rewarding the performer with additional social capital and status. This also has the effect of reinforcing the appropriateness of the act in that particular circumstance, transmitting to other potential performers in the future of the need to replicate that act or to surpass it in intensity or scope. A 
second possible outcome is that the performer misjudges the expectations of the audience and makes a performance that is inappropriate. It might be that the performer misidentified a potential target that then makes the whole group vulnerable. It might be that the intensity of the performance is inappropriate, either too weak or too extreme. Or possibly the scope the performance is inappropriate, again either too wide or too narrow. For example, the audience might see the performance as correct but targeting too many or too few members of the target group. In all of these cases of misjudgement the performer is not rewarded as he would have had the performance been judged by the audience as appropriate and correct. In some extreme cases, the performer may even lose social capital or social status. A third scenario might be that the audience did not at all expect the actions of the performer. In this case, the audience needs to adapt and respond to the new set of actions, whether in intensity, scope, location or as a wholly new set of actions to a familiar set of circumstances. The relationship between performer and audience is dynamic. It is not only the performer responding to audience expectations, or merely the audience judging the suitability of the performer's actions, each might surprise the other. In this case, the performers' action were wholly unanticipated, and the audience must now make a judgement. In such a set of circumstances we can also see that the audience is not unitary but collective. The audience is a social body in which the judgement must be derived, articulated, and transmitted both to the individual performer or performers, but also to the larger group. To derive this judgement, consensus must be achieved, but we might also imagine the political and social disagreements, the outcome of which may alter the actual distribution or the mode of distribution of social capital. Most often, the performer reinforces and retransmits the social mores and collective values of the group. However, in some circumstances, the performer may create a new performance or adapt a previous performance to a new circumstance, thereby forging a new set of performance values that will be taken up by the group and retransmitted through the judgements of the audience. The response of the group to this new adaptation sets the precedent for social capital accrual for other gang members in the future.

\section{Social Capital and Gang Initiation}

The concept of social capital has increasingly become influential within gang research and criminology in general (e.g. Deuchar 2009; Fraser 2015; Moule Jr. et al. 2013; Sandberg 2008; Sandberg and Fleetwood 2016; Shammes and Sandberg 2016). For example, scholarship discusses the role of social deprivation for social capital accumulation through gang membership (Deuchar 2009, 2011), the relation between sectarianism and social capital in gangs (Deuchar and Holligan 2010) and the role of social capital for fostering illegal economic activities of gangs (Kei-Ho Pih et al. 2008). Sandberg (2008) broadens the idea of social capital towards an analysis of cultural capital and street cultures which he analyses with the notion of "street capital" which refers to the competences and knowledge an individual possesses regarding the life in the street (see also Grundetjern and Sandberg 2012). Harding (2014) enhances the concept of "street capital" in his analysis of gangs in London by demonstrating how " $[\mathrm{t}]$ he neighbourhood brand name acts as a reputational moniker against which gang members' own street capital is ultimately measured" (2014: 157). Finally, scholars have discussed the relationship between violence and aggressive behaviour and social capital in gangs (Gatti and Tremblay 2007; McIlwaine and Moser 2001).

However, little research has been done on the relation between social capital and gang initiations. One exception is Moule Jr. et al.'s (2013) analysis of social capital and the life- 
course of gang members. Although the authors argue that "gangs are a source of social capital, allowing one entrance into an extended network of acquaintances" $(2013,147)$, they nevertheless conclude that joining a gang results "in an accelerating decline in social capital" (ibid.). Only at the beginning of membership does the social capital of the new gang member increase. However, the long-term consequences for his or her social capital are negative because the new gang member will lose his or her social network of friends outside the gang after being "jumped into" the gang (ibid.: 148). We forgo a deeper critical reflection on Moule Jr. et al.'s (2013) hypothesis that the long-term consequences of gang membership actually correlate with a loss of social capital, but rather we would like to focus on the onset of gang membership and the role of social capital within the same. In order to do so, it is, however, necessary to explicate the notion of social capital in more depth.

One of the most important scholars in the development of the concept of social capital has been Pierre Bourdieu. As pointed out by Murer, "for Bourdieu, [...] social networks are not given or natural but must be made through the active investment of time, energy, attention and effort to solidify group relations in such a way as to render them as resource for all the members" $(2014,296)$. Gangs comprise such social networks in which members are able to generate benefits by virtue of membership in this social network (see also Portes 1998, 6; Field 2008, 14). Put differently, gangs are social spaces - in Bourdieu's terminology "social fields" - which "are organised around everyday practices, assumptions, expectations, protocols, characteristic behaviours, and most of all, self-sustaining values" (Murer 2014, 297). For Bourdieu, "the active properties that are selected as principles of construction of the social space are the different kinds of power or capital that are current in the different fields" (1985, 724). Such kinds of capital are economic, cultural, social and symbolic capital, the latter referring to prestige, reputation, renown etc. (ibid.). Social capital, in turn, comprises "the aggregate of the actual or potential resources which are linked to possession of a durable network of more or less institutionalized relationships of mutual acquaintance and recognition" (Bourdieu 1986, 248). ${ }^{4}$ Bourdieu argues that these relationships may exist only in the practical state, in material and/or symbolic exchanges which help to maintain them. They may also be socially instituted and guaranteed by the application of a common name (the name of a family, a class, or a tribe or of a school, a party etc.) and by a whole set of instituting acts designed to simultaneously to form and inform those who undergo them $(1986,249)$.

Consequently, social capital refers to an actor's ability to secure certain benefits by virtue of membership in a social network or social structure (Portes 1998). Moreover, it informs about the social position of an individual within any social field, that is, his or her ability to adhere to a group's behavioural expectations (Murer 2014, 298).

This adherence to behavioural expectations, however, is not only limited to certain forms of "good" behaviour. Rather, as argued by Murer, "some actors may in fact accumulate social capital by violating norms of a larger group [e.g. society], as they are abiding by local

\footnotetext{
${ }^{4}$ With this understanding, Bourdieu (1986) differs from other important scholars in this field, especially Coleman (1988a, 1988b, 1990), who defined social capital as close and direct interpersonal relations and more as a by-product of activities engaged in for other purposes (1990: 312). For Coleman, one source of social capital is trust among the members of a collective group (see also Fukuyama 1995, 26; Portes and Sensenberger 1993), and he defines social capital by its function and as a source of social control (Portes 2000, 2). Another scholar worth noting here is Putnam $(1993,1996,2000)$. He argues that social capital "refers to features of social organization, such as networks, norms, and trust, that facilitate coordination and cooperation for mutual benefit" (1993: 1). For him, social capital tends to be self-reinforcing and cumulative and it enhances the benefits of investment in physical and human capital (ibid., 1, 4).
} 
expectations [e.g. by a gang]". Moreover, "if social capital can be seen as an embodied state of power, the ability to set expectation and norms - to contribute to the establishment of habitus, realised in practice - is a formidable social force" (2014, 298, original emphasis). Here, habitus refers to "a set of historical relations 'deposited' within individual bodies in the form of mental and corporal schemata of perception, appreciation and action" (Bourdieu and Wacquant 1992, 16); it comprises the social and cultural processes which invisibly govern and dictate practice within a social field (Murer 2014, 298). Thus, habitus is this form of power that determines which kind of behavioural practice receives support and consensus among the member of a social network and normalises them such that the power behind them goes unseen. "Habitus is both the generative principle of [...] classifiable judgements and the system of classification of these practices" (Bourdieu 2010 [1984], 166).

If one returns to the role of violence in the generation of reputation and social capital, it is possible to argue that status is afforded to those who best embody the values of the group, those that exhibit, embody and transmit the attributes of "common sense" will gain more status. If performing acts of violence is "common sense" in certain situations for actors in a given social field, then those who anticipate the context in which violence is expected, and become well versed in the nuances of the expected manner of such performance, will ultimately accumulate social capital (Murer 2014, 299, emphasis added).

This argument also upholds in the context of gang initiation rites in which social status is not so much attained to the performers of the violent act - the gang members who beat the prospective member - but rather to the prospect herself who, through her demonstration of toughness and resilience, communicates to the other gang members that she is tough enough to withstand physical violence. Put differently, the prospective member demonstrates that she is tough enough to take the beating without fighting back and that she is "good material for [the] gang” (Padilla 1992, 55; see also Descormiers and Corrado, 2016: 1342). In Bourdieu's terminology, withstanding violence during the initiation without fighting back is the resource of the aspirant to demonstrate her willingness to become a part of the group $(1986,248)$. In other words, the "youngsters' willingness to undergo and endure this vicious physical onslaught suggests high appraisal they give to the organization" (Padilla 1992, 59). This willingness is recognised by the other gang members with respect and appreciation which, in turn, increases the social capital and the social standing of the aspirant within the group. In the context of gang initiation rites, violence is therefore "not reactionary in the way that it is most often thought of, negatively, but is defensive and constructive" (Murer 2014, 300). It is constructive, as it enables the new gang member to create a reputation, social standing and recognition - in short, social capital - among his fellow peers in the gang. Concomitantly, this demonstration of toughness during the violent beating - the adherence to the values and norms of the gang-also strengthens the group cohesiveness and collective identity among the members of a gang who all went through the same violent initiation ritual.

This argument about the generation of social capital through the means of withstanding violence is also applicable to other violence performances. As mentioned above in reference to Murer's (2014) example of the two "street crews", in order to uphold the interests, norms and values of her own crew, the member uses violence in order to demonstrate her willingness to stand up for her own crew. This violent encounter with the opponent street crew increases the social standing and status of this member who commits the violent act among his peers: "in this case, violence is not maladaptive or anti-social, but rather is expected and constitutes the means to obtaining or accruing further social capital" $(2014,302)$. Utilising the notion of social capital from Bourdieu, we see that social status is created in social spaces - both physical and 
interpersonal - in which the social typology is determined according to the composition of the types of capital and power possessed within the group space. In this way, "agents and groups of agents are defined by their relative position in the social space [...] [where] the kinds of capital - like the aces in a game of card - are powers that define the chances of profit in a given field" (Bourdieu 1985, 725). The spaces can be physical, but they are mostly conceptual and relational. They are the spaces of social interaction and are the group community to which one feels attached and from which one derives one's sense of self-worth and validation. As such, Bourdieu offers that there may be multiple social spaces with differing modes of capital accumulation and accrual within the same or proximate physical spaces. Status is realised within these group, according to the distributions with these related social spaces. Thus, with the social environment of the gang space, the performances of violence, both in the ability to commit violence and to receive violence as ritual pain, are seen demonstrations of group membership and the basis of status accrual.

\section{Conclusion}

"I guess I took an ass whipping to be able to back up the barrio" (Vigil 1988, 438). This statement from an interview with a gang member exemplifies the role of violence in gang initiations. Violence in the context of gang initiation is "an action of creation" (Murer 2014, 311). It creates a social context in which the violent act of initiating a member is observed and determined by established gang members in accordance with the group's norms and values. It also creates a feeling of belonging for the aspirant who will gain recognition and respect from his or her fellow gang members after successfully going through the initiation. Violence in gang initiations therefore becomes a source of social capital and it binds the members of a gang together by means of a shared lieu de memoire associated with the gang. Hence, it constitutes a "ritualistic affair that is interwoven with the 'psychological moratorium' and the group psychology of the gang" (Vigil 1996, 152); an "immigration ceremony, granting membership in an ontologically higher order" (Katz 1988, 134). Therefore, violence stands at the beginning of every gang membership and becomes the central feature for creating a collective identity among the members of a gang. Additionally, "having passed the initiation test, gang members will no doubt be willing and ready to commit other acts of [...] violence" (Best and Hutchinson 1996, 399). Thus, violence during membership is a continuation of the experience of violence during the initiation rite, and it serves to maintain the collective identity of the gang and to increase one's social status. As stated by one Barrio 18 gang member who was chosen to commit a revenge attack against the rival MS-13 gang: "one of these days, we're going to go and shoot those fuckers. They're going to get it big time. They know... They can't mess with our gang.... If you get given a mission... You've got to go, for the cause. For the cause" (BBC 2006). ${ }^{5}$ In this reference to the cause, violence becomes an expression of a socially altruistic desire to serve the superior cause of the gang, ensuring the maintenance and reinforcement of the collective identity of the gang. Violence, then and during gang initiations, becomes a means to strengthen the social bonds among the members of a gang and it helps to create a collective identity among the same.

\footnotetext{
${ }^{5}$ This statement is part of the BBC (2006) documentary and can be found on https://www.youtube. com/watch?v=Usn-4aXhSYA (starts at minute 3.23) (Accessed 05 March 2016).
} 
We suggest in this paper the need for a new approach in addressing the issues of gang violence. At the heart of gang membership is often the issue of belonging, and the motivations for performing violence may be far from immediate. Rather, if we see the performance of violence, both in the willingness to experience violence as a mode of sacred and shared pain as a commitment to the group identity of the gang unit, and the willingness to commit violent acts against others as a demonstration of a different bodily commitment to the group, violence can only be ameliorated if another avenue of belonging and social capital accrual are proffered. Further, as the modes of social capital accumulation are immediate and actual for gang members, the offer of an alternative mode of accumulation must be equally clear regarding the path and terms of obtaining status. Perhaps most importantly, policy makers and community activists who wish to ameliorate the conditions of gang violence must understand that the modes of capital accumulation within the gang social space were attractive to members precisely because they felt excluded from more hegemonic or traditional avenues of social capital accumulation and status accrual. There cannot be an expectation that former gang members can simply, or easily, move into these more traditional or hegemonic forms. As succinctly stated by Deuchar (2018: 251) in his important work on gangs and spirituality, "transitioning away from masculine criminal distinction [...] and fully emasculating gang life and offending lifestyles was often hampered by lasting gang embodiment issues and stigmata". Leaving the violent context of gangs is difficult and closely dependent on gang members' ability to find social status and social capital outside of the gang context. This is not to say that social status or social capital accrued within the gang social space cannot be transferred or transformed. Quite to the contrary, it most certainly can. Social positions such as "violence interrupters" found in Chicago, associated with the community organisation, Cure Violence, are seen as important and trusted precisely because the holders of those positions have substantial social capital with the gang social space (National Institute of Justice 2009). For Bourdieu, there is a hierarchy of status associated with the proximity and distance to the "legitimate culture", which itself is "permanently in play... [as] an object of perpetual struggle" (Weininger 2002, 137). Yet those social groups lower in hierarchical rank often will not engage in any attempt to claim "cultural legitimacy" even as it is contested and in flux. Bourdieu suggest that this is because those furthest from the apex of cultural creation will seek out and create alternative modes of cultural production, the basis of "distinction", the eponymous concept at the heart of Bourdieu's analysis. Thus, an attempt to impose social status from above often de-legitimates the modes of social capital accumulation for those social groups lower in an overall cultural hierarchy. In some regards, this is the limit of power. The central "legitimate culture" may have so little legitimacy in alternative spaces that it cannot impose its judgement in those spaces and must acknowledge and work with those who are seen as possessing a high degree of social capital specific to the group social space. By seeing violence as a series of performances connected to social capital and status accrual, it is possible to reduce violence by recognising alternate modes of accumulation that are specific or local to a given social group space. Moreover, any intervention into such a social group space must take seriously the strength of the social bonds, and the intensity of emotional attachments to the group forged through rituals of pain. Encouraging young people to "simply walk away" from gang spaces does not recognise the intense bodily and emotional commitments made in the bonding of shared pain. Rather, the recognition of such endurance can be re-cast as strength to be transferred or transformed into a new social setting, perhaps one where violence can be eschewed precisely because its impacts are recognised and not dismissed. 
Open Access This article is licensed under a Creative Commons Attribution 4.0 International License, which permits use, sharing, adaptation, distribution and reproduction in any medium or format, as long as you give appropriate credit to the original author(s) and the source, provide a link to the Creative Commons licence, and indicate if changes were made. The images or other third party material in this article are included in the article's Creative Commons licence, unless indicated otherwise in a credit line to the material. If material is not included in the article's Creative Commons licence and your intended use is not permitted by statutory regulation or exceeds the permitted use, you will need to obtain permission directly from the copyright holder. To view a copy of this licence, visit http://creativecommons.org/licenses/by/4.0/.

\section{References}

Baird, A. (2017). Becoming the 'Baddest': masculine trajectories of gang violence in Medellín. Journal of Latin American Studies, 50(1), 183-210.

Bastian, B., Jetten, J., \& Ferris, L. J. (2014). Pain as social glue: shared pain increases cooperation. Psychological Science, 25(11), 2079-2085.

BBC. 2006. "18th street gang story" Part 3. (https://www.youtube.com/watch?v=Usn- 4aXhSYA) (Accessed 05 March 2016).

Beck, T. K. (2011). The eye of the beholder: violence as a social process. International Journal of Conflict and Violence, 5(2), 345-356.

Best, J., \& Hutchinson, M. M. (1996). The gang initiation rites as a motif in contemporary crime discourse. Justice Quarterly, 13(3), 383-404.

Bjerregaard, B., \& Lizotte, A. J. (1995). Gun ownership and gang membership. The Journal of Criminal Law and Criminology, 86(1), 37-58.

Bourdieu, P. F. (1985). The social space and the genesis of groups. Theory and Society, 14(6), 723-744.

Bourdieu, P.F. 1986. "The forms of capital." In Handbook of theory and research for the sociology of education edited by J.G. Richardson, 241-258 New York and London: Greenwood Press.

Bourdieu, P.F. 2010 [1984]. Distinction. London and New York: Routledge.

Bourdieu, P. F., \& Wacquant, L. (1992). An invitation to reflexive sociology. Chicago: The University of Chicago Press.

Bowman, G. 2001. "The violence in identity.” In Anthropology of violence and conflict edited by I. Schröder, and B. Schmidt, 25-46 London: Routledge.

Bufacchi, V. (2007). Violence and social justice. New York: Palgrave Macmillan.

Carlock, A.L., and Lizotte, A.J. 2015. "Gangs, guns, and violence. Synergistic effects." In The handbook of gangs, edited by S.H. Decker, and D.C. Pyrooz, 178-192 Malden et al.: John Wiley \& Sons, Inc.

Cobbina, J. E., Like-Haislip, T. Z., \& Miller, J. (2010). Gang fights versus cat fights: urban young men's gendered narratives of violence. Deviant Behavior, 31(7), 596-624.

Cohen, A. (2018). Youth gangs, violence, and local culture in Chiang Mai, Northern Thailand. Journal of Contemporary Ethnography, 47(4), 484-507.

Coleman, J. S. (1988a). The creation and destruction of social capital: implications for the law. Journal of Law, Ethics \& Public Policy, 3(3), 375-404.

Coleman, J. S. (1988b). Social capital in the creation of human capital. The American Journal of Sociology, 94, S95-S120.

Coleman, J. S. (1990). Foundations of social theory. Cambridge and London: The Belknap Press of Harvard University Press.

Dalal, F. (2009). “The paradox of belonging.” Psychoanalysis. Culture and Society, 13(1), 74-81.

Decker, S. (1996). Collective and normative features of gang violence. Justice Quarterly, 13(2), 243-264.

Decker, S. H., \& Van Winkle, B. (1996). Life in the gang: family, friends, and violence. New York: Cambridge University Press.

Descormiers, K., \& Corrado, R. R. (2016). The right to belong: individual motives and youth gang initiation rites. Deviant Behavior, 37(11), 1341-1359.

Deuchar, R. 2009. Gangs, marginalised youth and social capital. Stoke on Trent and Sterling: Trentham Books Limited.

Deuchar, R. (2010). It's just pure harassment... as if it's a crime to walk in the street': anti-social behaviour, youth justice and citizenship - the reality for young men in the East End of Glasgow. Youth Justice, 10(3), 258-274.

Deuchar, R. 2011. "'People look at us, the way we dress, and they think we're gangsters': bonds, bridges, gangs and refugees: a qualitative study of inter-cultural social capital in Glasgow." Journal of Refugee Studies 118. 
Deuchar, R. (2018). Gangs and spirituality. Global perspectives. Cham, Switzerland: Palgrave MacMillan.

Deuchar, R., \& Holligan, C. (2010). Gangs, sectarianism and social capital: a qualitative study of young people in Scotland. Sociology, 44(1), 13-30.

Dziewanski, D., 2020. "Femme fatales: girl gangsters and violent street culture in Cape Town." Feminist Criminology 1-26.

Emler, N., \& Reicher, S. (1995). Adolescence and delinquency. The collective management of reputation. Cambridge, MA: Blackwell Publishing Inc..

Fagan, J., and Wilkinson, D.L. 1998. Guns, "youth violence, and social identity in inner cities." Crime and Justice 24 (youth violence): 105-188.

Field, J. (2008). Social capital. London and New York: Routledge.

Fraser, A. (2015). Urban legends. Gang identity in the post-industrial city. Oxford: Oxford University Press.

Friedman, C. J., Mann, F., \& Friedman, A. S. (1975). A profile of juvenile street gang members. Adolescence X, 40, 563-607.

Fukuyama, F. (1995). Trust. The social virtues and the creation of prosperity. London: Hamish Hamilton Ltd..

Gatti, U., \& Tremblay, R. E. (2007). Social capital and aggressive behavior. European Journal on Criminal Policy and Research, 13, 235-249.

Girard, R. (1977). Violence and the sacred. London and New York: Continuum.

Glucklich, A., 2001. Sacred pain: hurting the body for the sake of the soul. Oxford University Press.

Grundetjern, H., \& Sandberg, S. (2012). Dealing with a gendered economy: female drug dealers and street capital. European Journal of Criminology, 9(6), 621-635.

Harding, S. (2014). The street casino: survival in violent street gangs. Bristol: Policy Press.

Heitmeyer, W., \& Anhut, R. (2008). Disintegration, recognition, and violence: a theoretical perspective. New Directions for Youth Development, 119, 25-37.

Hobsbawn, E. J. (1959). Primitive Revels. In Studies in archaic forms of social movement in the 19th and 20th centuries. Manchester: Manchester University Press.

Jankowski, M. S. (1991). Islands in the street: gangs and American urban society. Berkeley: University of California Press.

Karlin, M. (2008). Coming of age on the street: ritual invention and the sacred in American gang initiation rituals. The Council of Societies for the Study of Religion Bulletin, 37(3), 59-64.

Katz, J. (1988). Seductions of crime. Moral and sensual attractions in doing evil. New York: Basic Books.

Kei-Ho Pih, K., De La Rosa, M., Rugh, D., \& Mao, K. (2008). Different strokes for different gangs? An analysis of capital among Latino and Asian gang members. Sociological Perspectives, 51(3), 473-494.

Kurtz, L.R., and Turpin, J. 1997. "Conclusion: untangling the Web of violence.” In The web of violence. From interpersonal to global edited by J. Turpin, and L.R. Kurtz, 207-232 Urbana and Chicago: University of Illinois Press.

Lauger, T. R. (2020). Gangs, identity, and cultural performance. Sociology Compass, 14(4), 1-12.

Lende, D. H. (2014). Comments on 'The ties that bind us: ritual, fusion, and identification'. Current Anthropology, 55(6), 686-687.

McIlwaine, C., \& Moser, C. O. N. (2001). Violence and social capital in urban poor communities: perspectives from Colombia and Guatemala. Journal of International Development, 13, 965-984.

Morinis, A. (1985). The ritual experience: pain and the transformation of consciousness in ordeals of initiation. Ethos, 13(2), 150-174.

Moule Jr., R.K., Decker, S., and Pyrooz, D.C. 2013. "Social capital, the life-course, and gangs". In Handbook of life-course criminology. Emerging trends and directions for future research. Edited by C.L. Gibson, and M.D. Krohn, 143-158 New York: Springer.

Murer, J. S. (2009). Constructing the enemy-other: anxiety, trauma and mourning in the narratives of political conflict. Psychoanalysis, Culture \& Society, 14(2), 109-130.

Murer, J.S. 2014. "Understanding collective violence: the communicative and performative qualities of violence in acts of belonging". In International criminal law and criminology edited by I. Bantekas, 287-315 Cambridge: Cambridge University Press.

National Institute of Justice 2009. Who are the Violence Interrupters? (https://www.nij.gov/journals/264 /pages/ceasefire-interrupters.aspx) (Accessed 21 July 2018).

Ness, C. D. (2004). Why girls fight: female youth violence in the Inner City. The Annals of the American Academy of Political and Social Science, 595(1), 32-48.

Otto, N. (2020). "I did what I had to do": loyalty and sacrifice in girls' narratives of homicide in Southern Brazil. British Journal of Criminology, 60(3), 703-721.

Padilla, F. M. (1992). The gang as an American enterprise. New Brunswick: Rutgers University Press.

Papachristos, A. V. (2009). Murder by structure: dominance relations and the social structure of gang homicide. The American Journal of Sociology, 115(1), 74-128. 
Portes, A. (1998). Social capital: its origins and applications in modern sociology. The Annual Review of Sociology, 24, 1-24.

Portes, A. (2000). The two meanings of social capital. Sociological Forum, 15(1), 1-12.

Portes, A., \& Sensenberger, J. (1993). Embeddedness and immigration: notes on the social determinants of economic action. American Journal of Sociology, 98(6), 1320-1350.

Putnam, R. D. (1993). The prosperous community. Social capital and public life. The American Prospect, 4(13), $35-42$.

Putnam, R.D. 1996. "Who killed civic America?" Prospect: 66-73.

Putnam, R. D. (2000). Bowling alone. The collapse and revival of American community. New York: Touchstone.

Riches, D. 1986. "The phenomenon of violence." In The anthropology of violence edited by D. Riches, 1-27 Oxford: Basil Blackwell ltd.

Salo, E., 2007. "Mans is ma soe." In States of violence: politics, youth, and memory in contemporary Africa, 148-178 London: University of Virginia Press.

Sandberg, S. (2008). Street capital. Ethnicity and violence on the streets of Oslo. Theoretical Criminology, 12(2), 153-171.

Sandberg, S., \& Fleetwood, J. (2016). Street talk and Bourdieusian criminology: bringing narrative to field theory. Criminology \& Criminal Justice, 17(4), 1-17.

Scarry, E. (1985). The body in pain: the making and unmaking of the world. New York: Oxford University Press.

Schröder, I., and Schmidt, B. 2001. "Introduction: violent imaginaries and violent practices." In Anthropology of violence and conflict edited by B. Schmidt, and I. Schröder, 1-21 London: Routledge.

Shammes, V. L., \& Sandberg, S. (2016). Habitus, capital, and conflict: bringing Bourdieusian field theory to criminology. Criminology \& Criminal Justice, 16(2), 195-213.

Simmel, G. 1950. “The secret society.” In The Sociology of Georg Simmel edited by K.H. Wolff New York: The Free Press.

Skarbek, D., \& Wang, P. (2015). Criminal rituals. Global Crime, 16(4), 288-305.

Skerrett, K. R. (2002). Sacred pain: hurting the body for the sake of the soul by Ariel Glucklich. The Journal of Religion, 82(4), 681-682.

Spergel, I. A. (1995). The youth gang problem. New York: Oxford University Press.

Stretesky, P. B., \& Pogrebin, M. R. (2007). Gang-related gun violence. Socialization, identity, and self. Journal of Contemporary Ethnography, 36(1), 85-114.

Vigil, J. D. (1988). Group processes and street identity: adolescent Chicano gang members. Ethos, 16(4), 421445.

Vigil, J. D. (1996). Street baptism: Chicano gang initiation. Human Organization, 55(2), 149-153.

Volkan, V. D. (2009). Large group identity: "Us and them" polarizations in the international arena. Psychoanalysis, Culture \& Society, 14(1), 4-15.

Weininger, E.B. 2002. "Pierre Bourdieu on social class and symbolic violence." In. Alternative Foundations of Class Analysis. Cambridge edited W.E. Olin Cambridge: Cambridge University Press.

Whitehouse, H., \& Lanman, J. A. (2014). The ties that bind us: ritual, fusion, and identification. Current Anthropology, 55(6), 674-695.

Wood, J. L. (2014). Understanding gang membership: the significance of group processes. Group Processes \& Intergroup Relations, 17(6), 710-729.

Xygalatas, D., Mitkidis, P., Fischer, R., Reddish, P., Skewes, J., Geertz, A. W., Roepstorff, A., \& Bulbulia, J. (2013). Extreme rituals promote prosociality. Psychological Science, 24(8), 1602-1605.

Xygalatas, D., Khan, S., Lang, M., Kundt, R., Kundtová-Klocová, E., Krátký, J., \& Shaver, J. (2019). Effects of extreme ritual practices on psychophysiological well-being. Current Anthropology, 60(5), 699-707.

Publisher's Note Springer Nature remains neutral with regard to jurisdictional claims in published maps and institutional affiliations. 